\title{
Prototype for Automatic Control for Extraction of Bio-Crude from Waste Tyres using IoT
}

\author{
Mr. Mohammed Layeeq U R Rahman \\ Dept pf Electronics and Instrumentation \\ P.D.A College of Engineering \\ Kalaburagi Karnataka India
}

\author{
Dr. Channapa Bhyri \\ Professor (H.O.D) \\ P.D.A College of Engineering \\ Kalaburagi Karnataka India
}

\begin{abstract}
The prototype for Automatic control for Extraction of bio-crude from waste tyres. In this system the automatic control of heating system is done by using a electric heater as heating source. Solenoid valve is used for maintaining the parameters such as Flow level and temperature $T_{1}$ and $T_{2}$ and heater for temperature $T_{3}$ via $I o T$ is done through ATmega328P microcontroller. The system helps the industry with all automatic controls and monitoring for the complete plant/Industry was designed on the mobile phone/PC even far away from the industry via IoT. The user can monitor and control the process both by automatic and manual method (i.e. Complete Shutdown of the process just by a one click in any of the emergency situations). The microcontroller is the most important unit of this system. Node MCU is a microcontroller which is connected to IOT server through internet. MCU will receive the ON/OFF packets from server and switches appliances respect to server signal. Relay is an electromagnetic device used for actuating the actuators.
\end{abstract}

\section{INTRODUCTION}

The Proposed prototype system is based on the Automatic control for Extraction of bio-crude from waste tyres. The proposed prototype system is designed with the automatic control of

1) Heating system for boiling water (burning tyres),

2) Operation of solenoid valve for maintaining the Flow parameters via IoT through ATmega328P microcontroller.

Initially the process was carried out completely by manual process such as opening/closing of valves, control of heating process etc. Later on the industry established partial automatic process in which a efforts were made less for monitoring the values of the instruments installed. Whereas the proposed system helps the industry with all automatic controls and monitoring for the complete plant/Industry on the mobile phone/PC even far away from the industry via IoT. The user can monitor and control the process both by automatic and manual method (i.e. Complete Shutdown of the process just by a one click in any of the emergency situations).

One of the main challenges of modern society is the rising rate of solid waste generated by man's activities which has poised a major environmental concern. The disposal of used tyres and other polyisoprene based products is a large fraction of such problems as 1.3 billion tyres are estimated to reach their end of life cycle annually worldwide. They are not biologically degradable leading to problems with their disposal. Hence recycling of the tyres was initated by the process named as PYROLYSIS. Pyrolysis mainly involve the decomposition of polyisoprene materials to low molecular weight component at high temperature $\left(250^{\circ} \mathrm{C}-\right.$ $900^{\circ} \mathrm{C}$ ) in an inert atmosphere.

\section{METHODS OF RECYCLING OF USED TYRES}

The various methods in which used tyres are recycled are

1. Retreading Method

2. Mechanical or Cryogenic Method

3. Reclaiming Rubber Raw Materials Methods.

\section{A. Retreading Method}

Retread also referred to as "remold" involves buffing away of the remaining tread in a spent tyre and replacing it with a new tread rubber strip by vulcanization. It is carried out only on used tyres casing that have been inspected and repaired. Although it is economically advantageous, product quality confidence is a major challenge of the process.

\section{B. Mechanical or Cryogenic Method}

Both mechanical and cryogenic (grinding of waste tyres at temperatures of $-80^{\circ} \mathrm{C}$ to $-100^{\circ} \mathrm{C}$ using liquid nitrogen) recycling of used tyres involve the milling of tyres to produce ground rubber of different particle sizes. The fine grounded rubber can be used in varieties of application such as an additive in road asphalting, sports and children playground surfacing, carpets, and other rubber products. However, the limited market for the product and a high cost of running the process are a disadvantage.

C. Reclaiming Rubber Raw Materials Methods.

Different methods and processes for reclaiming rubber have been developed. The most relevant of them are

1. Thermo mechanical reclaiming

2. microwave reclaiming

3. mechanical shearing process

4. Reclaiming by biotechnological process

5. Ultrasonic reclaiming

6. Reclaiming by renewable resource materials

7. Reclaiming by use of different chemical agents and

8. Pyrolysis of waste tyre

These methods actually help in transforming used tyres from a three dimensionally interlinked thermoses polymer state to a two dimensional polymer exhibiting the properties of a virgin rubber. The high cost of the process, quality of products, and lack of acceptance of reclaim rubber by industries as a raw material are a setback on the process. Although used tyres can be used as a source of fuel in cement kilns by combustion method, it is not economically wise and environmentally friendly. 


\section{PYROLYSIS, PROCESS CONDITIONS, AND REACTORS}

Pyrolysis mainly involves the thermal degradation of tyre rubber at high temperatures $\left(250^{\circ} \mathrm{C}-900^{\circ} \mathrm{C}\right)$ in oxygen absent environment. It can be performed under vacuum or atmospheric flow. Amongst other methods such as combustion and gasification used to extract energy from biomass, pyrolysis has received more attention in the area of research because the process conditions can be optimized to produce high energy density liquids, char, and gas.

\section{Pyrolysis Reactors}

The reactor is a very important part of the pyrolysis process. Over the years, the innovation and technological advancement of pyrolysis has advanced considerably. Researchers have developed and studied different reactors and processes to the point where pyrolysis is now an acceptable technique to the deriving of gaseous, liquid, solid fuels, and chemicals.

\section{E. Types of Pyrolysis}

a) Slow Pyrolysis

b) Fast Pyrolysis

c) Catalytic Pyrolysis

d) Flash Pyrolysis

- Slow Pyrolysis

The solid residence time(s) in the reactor is $\left(450^{\circ} \mathrm{C}-550^{\circ} \mathrm{C}\right)$, heating rate is $0.1-1$, and feed particle size $(5 \mathrm{~mm}-50 \mathrm{~mm})$ is with temperature of $\left(550^{\circ} \mathrm{C}-950^{\circ} \mathrm{C}\right)$. This process enhances char production and is unlikely to be unsuitable for high quality bio-oil production. Also, due to high residence time secondary reaction is favorable as cracking of primary product occurs.

\section{- Fast Pyrolysis}

Fast pyrolysis involves the rapid heating of the feed material to a high temperature in the absence of oxygen with a short residence time of the condensable vapor in the reactor. Its operating parameters are solid residence time between $(0.5-10 \mathrm{~s})$, heating rate of $\left(10^{\circ} \mathrm{C}-200^{\circ} \mathrm{C}\right)$, feed particle size less than $5 \mathrm{~mm}$, and reaction temperature of $\left(550^{\circ} \mathrm{C}-1200^{\circ} \mathrm{C}\right)$. The technology has received much popularity in producing liquid fuels and a range of specialty and commodity chemicals. Typically on weight basis, fast pyrolysis yields $60 \%-75 \%$ pyro-oil with $15 \%-25 \%$ compared to other processes; it has reasonably low investment costs and high energy efficiencies particularly on a small scale.

\section{- Flash Pyrolysis}

This process is characterized by residence time of less than $0.5 \mathrm{~s}$, high heating rate of more than $200^{\circ} \mathrm{C}$, particle size of less than $0.2 \mathrm{~mm}$, and high reaction temperature of more than $1000^{\circ} \mathrm{C}$. However, the major technological challenge of the process is poor thermal stability, solids in the oil, and production of pyrolytic water.

\section{a) Catalytic Pyrolysis}

Catalytic pyrolysis is a pyrolysis process that includes the use of a catalyst. The catalyst helps enhance the pyrolysis reaction kinetics by cracking down higher molecular weight hydrocarbon compounds to lighter hydrocarbon products. It has been reported that the use of catalyst in tyre pyrolysis systems can greatly influence the composition, quality, and yield of products.

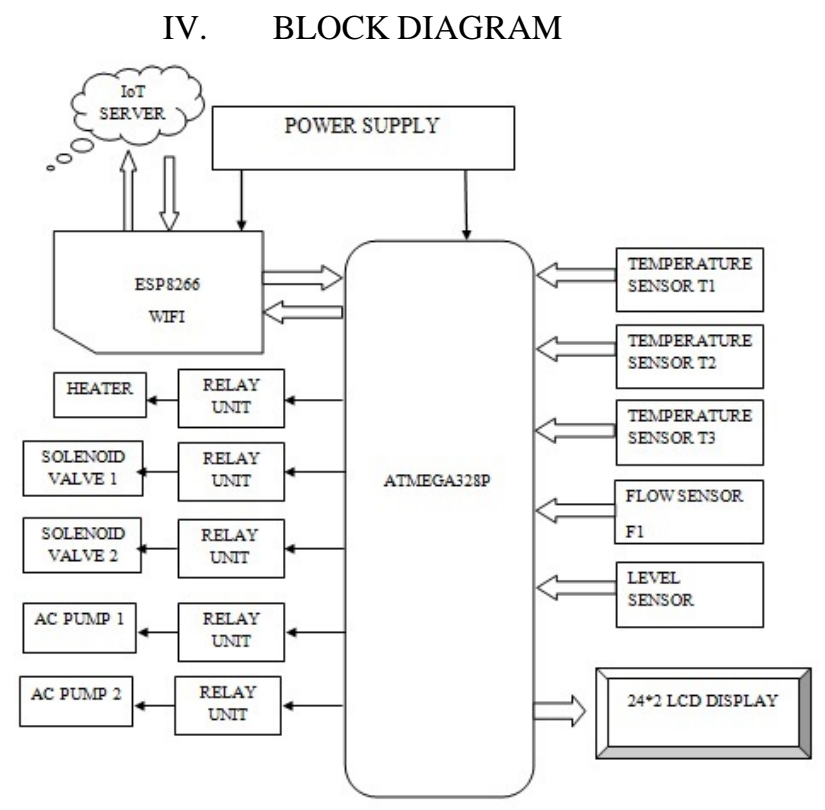

Fig. 1. BLOCK DIAGRAM OF COMPONENTS

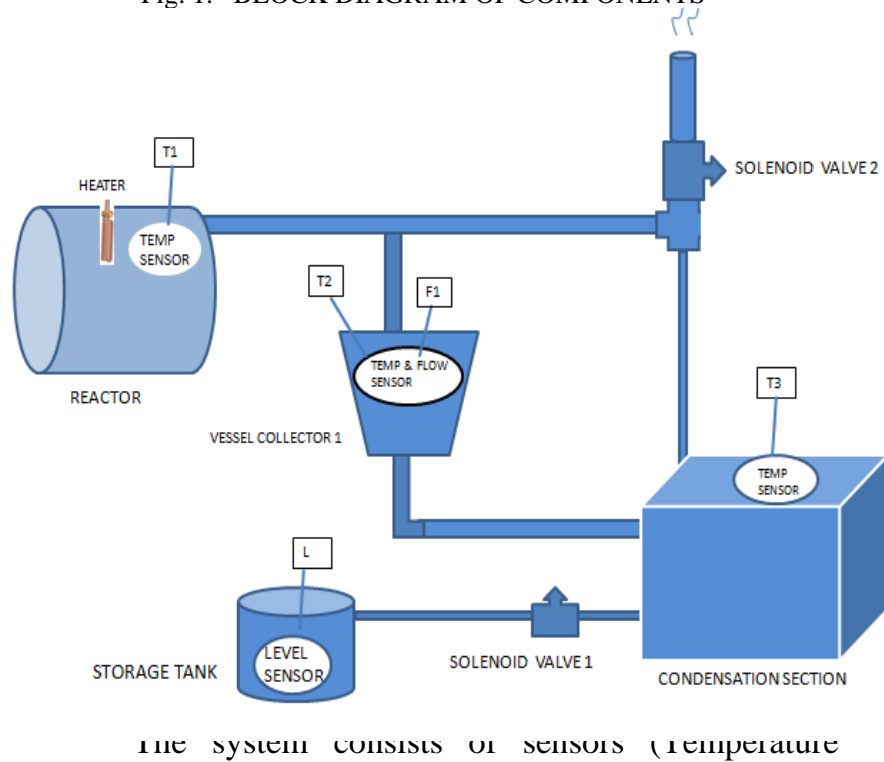

sensor $T_{1}$ and $T_{2}$, flow sensor and level sensor) for measuring the parameters in the process, actuators (Heating element, Pump and Solenoid valves $S_{1}$ and $S_{2}$ ) for mainting the Set-Point of the respective parameters these actuators are energized by relay unit through the Microcontroller (Atmega328P) which is main processing unit. All sensors, actuators, relay unit, display, and Wi-Fi module are connected to the microcontroller. By making use IoT the person can be able to access the data for monitoring as well as controlling the parameters in any location away from the industry.

The sensors will be well placed at specific position in the model for sensing the various parameters. The Wi-Fi module (ESP8266) will be placed along with the microcontroller so that the data from microcontroller can be received and sent to the IoT cloud/Server which can be accessed via login id and password in Smartphone/laptop/pc 
which has internet connectivity. The data received will be shown on the dashboard of IoT server (Adafruit Io). Any changes made on dashboard for the parameter set points or actuators state (on/off) will be reflected back to the microcontroller. And the system will start working based the changes made on the dashboard.

\section{COMMUNICATION}

Communication is the activity of conveying information through the exchange of messages, or information. The system which is to displays the next station information. To establish the communication between the station and train we using RF communication system.

\section{F. Block diagram of Communication System}

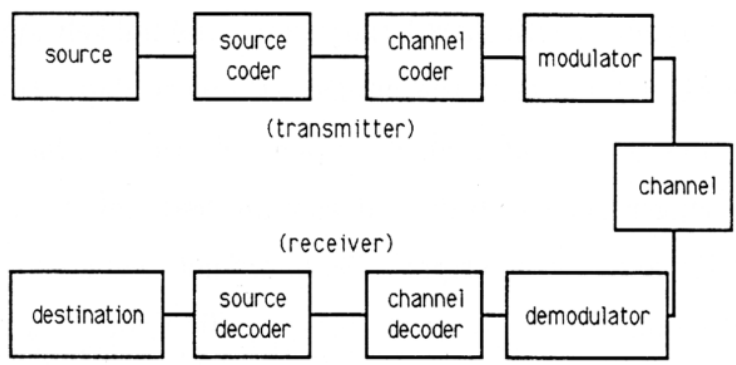

Fig. 3. Block diagram of Communication System

a) Transmitter: Transmitter is the transmitting part in this block diagram. Using this system we can generate the messages which are to be sent through this system.

b) Receiver: This is the Receiving part in block diagram of communication system. This can be said as the target to which the information needs to be delivered.

c) Encoder: Encoder is the second element in the communication system. It performs the encoding of the given data, which means that this system converts the messages in the form of symbols for transmission purpose. In this system, sequences of characters are created in a special format for an effective transmission. This encoding system is used for security purpose.

d) Decoder: Decoder is used to decode the encoded message and retrieve the actual message. Decoding must be done correctly. If this part is not performed well then the message which is received might not be correct.

e) Channel: This is the main block in the block diagram of communication system. Noisy channel is nothing but the medium through which the message is transmitted. Messages are conveyed through this channel. Different channels have different strengths and weaknesses. Each channel has its own frequency and different applications have different operating frequencies.

f) Modulation and demodulation: Modulation is a process, in which any one of the characteristics (Amplitude, Phase, and Frequency) of carrier wave is varied in accordance with the message signal. Retrieving the original message signal from the Modulated signal is known as Demodulation.
G. Node MCU (ESP8266):
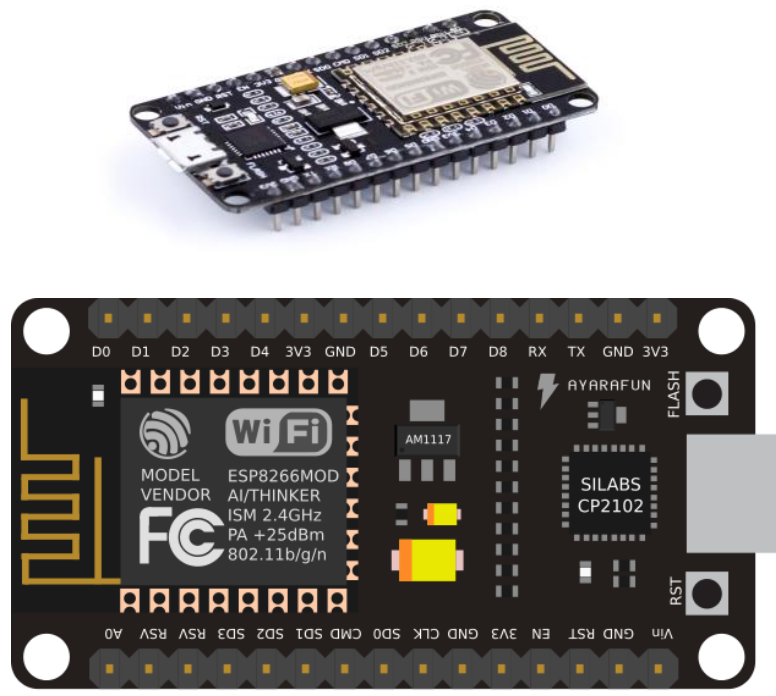

Fig. 4. ESP8266EX

Node MCU is a microcontroller which is connected to IOT server through internet. MCU will receive the $\mathrm{ON}$ OFF packets from server and switches appliances respect to server signal. Expressive Systems' Smart Connectivity Platform (ESCP) is a set of high performance, high integration wireless SOCs, designed for space and power constrained mobile platform designers. It provides unsurpassed ability to embed Wi-Fi capabilities within other systems, or to function as a standalone application, with the lowest cost, and minimal space requirement.

ESP8266EX offers a complete and self-contained WiFi networking solution; it can be used to host the application or to offload WiFi networking functions from another application processor. When ESP8266EX hosts the application, it boots up directly from an external flash. In has integrated cache to improve the performance of the system in such applications. Alternately, serving as a Wi-Fi adapter, wireless internet access can be added to any micro controller based design with simple connectivity (SPI/SDIO or I2C/UART interface).

\section{H. IOT SERVER:}

IoT server will triggered by the IFTTT server i.e it send the ON OF commands packets to the Node MCU ecp8266.

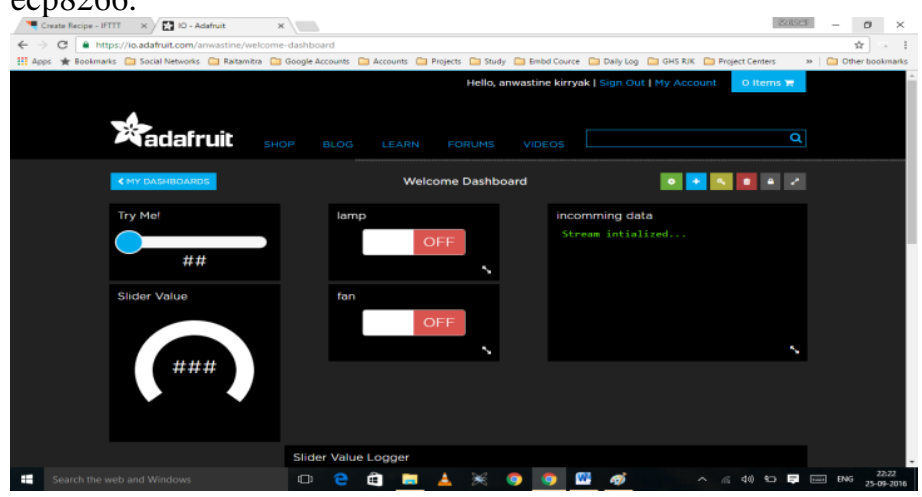


- Adafruit IO is a system that makes data useful. Our focus is on ease of use, and allowing simple data connections with little programming required.

- IO includes client libraries that wrap our REST and MQTT APIs. IO is built on Ruby on Rails, and Node.js.

- Adafruit IO is currently in beta. If you would like to join the beta, head over to io.adafruit.com to sign up.

- IoT is the network of physical devices, vehicles, buildings and other items embedded with electronics, software, sensors, actuators, and network connectivity that enable these objects to collect and exchange data. In 2013 the Global Standards Initiative on Internet of Things (IoT-GSI) defined the IoT as "the infrastructure of the information society." The IoT allows objects to be sensed and/or controlled remotely across existing network infrastructure. creating opportunities for more direct integration of the physical world into computerbased systems, and resulting in improved efficiency.

\section{RESULTS}

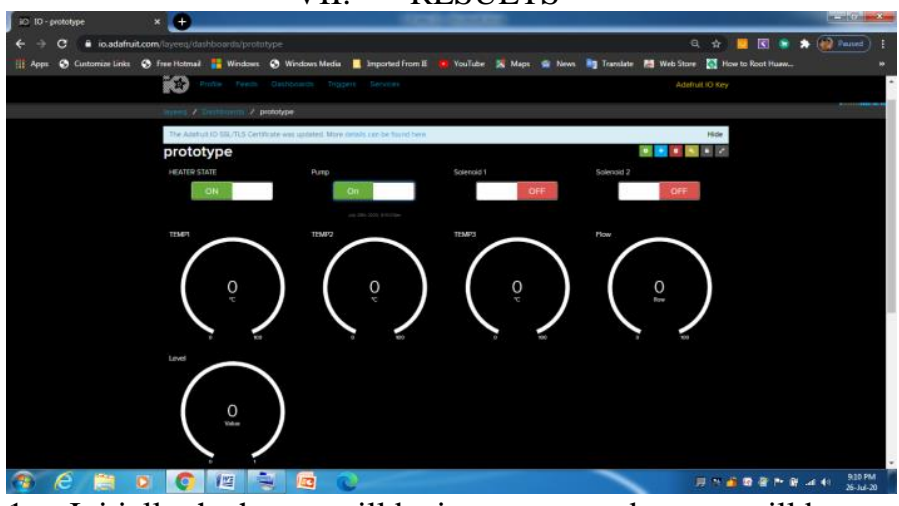

1. Initially the heater will be in on state and pump will be in off state, while pump and solenoid valves will be off as the tempT1 reads value more than set point the pump will turn on and heater turn off automatically.

2. When temp T2 and Flow F exceeds set point value the Solenoid valve 1 will turn on to maintain the set points.

3. The solenoid valve 2 will be actuated when temp T3 will be reaching its set point.

Level L will update the level of product collected in final stage.

\section{CONCLUSION}

In this system the automatic control of heating system is done by using a electric heater as heating source, solenoid valve is used for maintaining the parameters such as FLOW, and level via IoT is done through ATmega328P microcontroller. The system helps the industry with all automatic controls and monitoring for the complete plant/Industry was designed on the mobile phone/PC even far away from the industry via IoT. The user can monitor and control the process both by automatic and manual method (i.e. Complete Shutdown of the process just by a one click in any of the emergency situations).

The microcontroller is the most important unit of this system. Node MCU is a microcontroller which is connected to IOT server through internet. MCU will receive the ON OFF packets from server and switches appliances respect to server signal. Relay is an electromagnetic device which is used to isolate two circuits electrically and connect them magnetically. The LM35 series are precision integrated-circuit temperature devices with an output voltage linearly-proportional to the Centigrade temperature. 20x4 LCD module displays 20 characters wide, 4 rows character A power supply (sometimes known as a regulated power supply unit or RPSU) is a device or system that supplies electrical or other types of energy to an output load or group of loads.

\section{ACKNOWLEDGMENT}

I am thankful to my guide, Prof. Channapa bhyri for his constant encouragement, guidance and for thecontinues support in making this work complete.

\section{REFERENCES}

[1] O.Do'gan , M. B. Elik, and B.”Ozdalyan, "The effect of tirederived fuel/diesel fuel blends utilization on diesel engine performance and emissions," Fuel, vol. 95, pp. 340-346, 2012.

[2] S. Murugan, M. C. Ramaswamy, and G. Nagarajan, "The use of tyre pyrolysis oil in diesel engines,"Waste Management, vol. 28, no. 12 , pp. 2743-2749, 2008.

[3] S. Ucar, S. Karag'oz, J. Yanik, M. Saglam, and M.Yuksel, "Copyrolysis of scrap tires with waste lubricant oil," Fuel Processing Technology, vol. 87, no. 1, pp. 53-58, 2005.

[4] E. O. Doebelin and D. N. Manik, "Measurement systems: application and design," 2007.

[5] W. Golding, "Electrical measurements and measuring instruments," vol. 5, 2009

[6] S. C. Mukhopadhyay and N. Suryadevara, "Internet of things: Challenges and opportunities," in Internet of Things. Springer, 2014, pp. $1-17$

[7] G. C. Meijer et al., Smart sensor systems. Wiley Online Library, 2008

[8] H. Ghayvat, S. Mukhopadhyay, J. Liu, A. Babu, M. E. E. Alahi, and X. Gui, "Internet of things for smart homes and buildings," Australian Journal of Telecommunications and the Digital Economy, vol. 3, no. 4, 2015. 